\title{
Clade C HIV-1 isolates circulating in Southern Africa exhibit a greater frequency of dicysteine motif-containing Tat variants than those in Southeast Asia and cause increased neurovirulence
}

Vasudev R Rao', Ujjwal Neogi ${ }^{2}$, Joshua S Talboom³,4, Ligia Padilla ${ }^{5}$, Mustafizur Rahman ${ }^{6}$, Cari Fritz-French', Sandra Gonzalez-Ramirez ${ }^{8}$, Anjali Verma ${ }^{10}$, Charles Wood ${ }^{8}$, Ruth M Ruprecht ${ }^{9}$, Udaykumar Ranga $^{10}$, Tasnim Azim ${ }^{6}$, John Joska ${ }^{11}$, Eliseo Eugenin ${ }^{12,13}$, Anita Shet ${ }^{2}$, Heather Bimonte-Nelson ${ }^{3,4}$, William R Tyor 5,7,8,14 and Vinayaka R Prasad ${ }^{1 *}$

\begin{abstract}
Background: HIV-1 Clade C (Subtype C; HIV-1C) is responsible for greater than 50\% of infections worldwide. Unlike clade B HIV-1 (Subtype B; HIV-1B), which is known to cause HIV associated dementia (HAD) in approximately 15\% to $30 \%$ of the infected individuals, HIV-1C has been linked with lower prevalence of HAD (0 to 6\%) in India and Ethiopia. However, recent studies report a higher prevalence of HAD in South Africa, Zambia and Botswana, where HIV-1C infections predominate. Therefore, we examined whether Southern African HIV-1C is genetically distinct and investigated its neurovirulence. HIV-1 Tat protein is a viral determinant of neurocognitive dysfunction. Therefore, we focused our study on the variations seen in tat gene and its contribution to HIV associated neuropathogenesis.

Results: A phylogenetic analysis of tat sequences of Southern African (South Africa and Zambia) HIV isolates with those from the geographically distant Southeast Asian (India and Bangladesh) isolates revealed that Southern African tat sequences are distinct from Southeast Asian isolates. The proportion of HIV - 1C variants with an intact dicysteine motif in Tat protein (C30C31) was significantly higher in the Southern African countries compared to Southeast Asia and broadly paralleled the high incidence of HAD in these countries. Neuropathogenic potential of a Southern African HIV-1C isolate (from Zambia; $\left.H I V-1 C_{1084 i}\right)$, a HIV-1C isolate (HIV-1 IndieC1) from Southeast Asia and a HIV-1B isolate (HIV-1 $\left.{ }_{A D A}\right)$ from the US were tested using in vitro assays to measure neurovirulence and a SCID mouse HIV encephalitis model to measure cognitive deficits. In vitro assays revealed that the Southern African isolate, $\mathrm{HIV}-1 \mathrm{C}_{1084 i}$ exhibited increased monocyte chemotaxis and greater neurotoxicity compared to Southeast Asian HIV-1C. In neurocognitive tests, SCID mice injected with MDM infected with Southern African HIV-1C $1084 i$ showed greater cognitive dysfunction similar to HIV-1B but much higher than those exposed to Southeast Asian HIV $-1 \mathrm{C}$.

(Continued on next page)
\end{abstract}

\footnotetext{
*Correspondence: vinayaka.prasad@einstein.yu.edu

${ }^{1}$ Department of Microbiology and Immunology, Albert Einstein College of

Medicine, 1300 Morris Park Avenue, Bronx, NY 10461, USA

Full list of author information is available at the end of the article
} 
(Continued from previous page)

Conclusions: We report here, for the first time, that HIV-1C from Southern African countries is genetically distinct from Southeast Asian HIV-1C and that it exhibits a high frequency of variants with dicysteine motif in a key neurotoxic HIV protein, Tat. Our results indicate that Tat dicysteine motif determines neurovirulence. If confirmed in population studies, it may be possible to predict neurocognitive outcomes of individuals infected with HIV-1C by genotyping Tat.

Keywords: Clade C HIV-1, Subtype C HIV-1, HIV-1 Tat, Tat dicysteine, Neuropathogenesis, SCID-HIVE mouse model, HIV-1 Tat C31S polymorphism, Neuroaids, HIV dementia

\section{Background}

Human immunodeficiency virus type 1 (HIV-1) associated neurocognitive disorders (HAND) comprise a spectrum of conditions that range from asymptomatic neurocognitive impairment (ANI) and mild neurocognitive disorder (MND) to the most severe form, HIV-associated dementia (HAD) [1]. Distinct clades of HIV-1 or their recombinants dominate a given geographic region. $\mathrm{HIV}-1 \mathrm{C}$, the predominant clade prevalent in Africa and Southeast Asia, is responsible for greater than $50 \%$ of all new infections worldwide [2]. Studies have reported a lower prevalence $(0 \%-6 \%)$ of HAD in countries where HIV-1C is the dominant clade (e.g., India, Ethiopia) [3,4]. This is in contrast to studies in geographic regions (E.g., United States) that show higher prevalence of HAD (15 - 30\%) where HIV-1B is prevalent $[5,6]$.

HIV-1 Tat protein is one of the key viral determinants of neurocognitive disorders [7] Infiltration of mononuclear phagocytes in brain tissue is a hallmark of HAD. Tat, in addition to its key role in LTR-transactivation during viral replication, plays a pivotal role in monocyte chemotaxis and neurotoxicity. Monocyte chemotaxis driven by Tat is mediated by both direct and indirect processes. Direct chemotaxis has been demonstrated in vitro using recombinant Tat protein and this activity of Tat has been mapped to the C30C31 dicysteine motif in Tat $[8,9]$. Such a dicysteine motif is also a key feature of $\beta$-chemokines such as CCL2, MIP1 $\alpha$ and RANTES [8]. Tat has also been shown to induce the secretion of CCL2 from HIV-infected macrophages thus amplifying the chemokine gradient which help recruit additional mononuclear phagocytes across the blood-brain barrier into the brain $[10,11]$. This property of Tat is based on its homology to CCL2 and its ability to bind to CCR2 which triggers the induction of CCL2 by macrophages exposed to Tat or HIV-infected cells [12]. The infiltration of HIV - infected macrophages in the brain leads to the secretion of viral proteins such as Tat and gp120, both of which have been shown to be neurotoxic $[13,14]$. In vivo, the presence of HIV proteins is known to result in the loss of integrity of neuronal dendritic arbor in frontal lobe and hippocampus and this is associated with neuronal apoptosis [7,15-17].
We previously showed that in $\sim 90 \%$ of clade C HIV isolates, tat gene displays a $\mathrm{C} 31 \mathrm{~S}$ polymorphism and is defective for monocyte chemotaxis [18]. In vitro Boyden chamber assays using HIV-infected monocyte-derived macrophage (MDM) supernatants showed that monocyte recruitment by the Indian clade $\mathrm{C} \mathrm{HIV}-1 \mathrm{C}_{\text {IndieC1}}$-infected medium was significantly lower than that by the US clade B HIV-1B $B_{A D A}$ [19]. Depletion of Tat protein from the HIV-infected MDM supernatants by immune-adsorbtion abrogated the differential monocyte recruitment by the two clades of HIV-1. Based on these findings, we had proposed that the chemotaxis defect associated with Tat C31S polymorphism is responsible for the lower prevalence of HAD in India [18]. We used a severe combined immunodeficiency (SCID) HIV Encephalitis (HIVE) mouse model in which intracranial injection of clade B HIV-infected MDMs leads to neuropathology and neurocognitive defects that parallel those found in HAD patients [20,21]. In this model, clade $\mathrm{C} \mathrm{HIV}$ IndieC1 isolate caused milder neuropathology and reduced neurocognitive deficits compared with clade $B$ isolate $\left(\mathrm{HIV}-1 \mathrm{~B}_{\mathrm{ADA}}\right)$ [19]. To understand the mechanism underlying clade differences between $\mathrm{B}$ and $\mathrm{C}$ Tat proteins, Campbell et al. examined Tat-binding to CCR2, intracellular calcium release in response to CCR2Tat interaction, monocyte migration and the induction of TNF- $\alpha$ [22]. They showed that while clade B Tat specifically binds CCR2, induces robust levels of intracellular calcium influx and TNF- $\alpha$ and causes monocyte migration, clade C Tat (with a C31S substitution) was defective for these functions. In addition to the induction of CCL2, it is known that HIV-1 Tat induces several proinflammatory cytokines. Several groups have shown that in vitro purified recombinant HIV-1B Tat induces monocytes to produce proinflammatory cytokines to a greater extent than does HIV-1C Tat [22-25].

The mechanism of neurotoxicity of HIV-1 Tat protein is N-methyl-d-aspartic acid (NMDA) receptor-dependent. Two main mechanisms of NMDA receptor activation by HIV-Tat have been described. In one, an interaction of HIV-Tat with surface receptors, such as low-density lipoprotein receptor-related protein (LRP) and formation of a macromolecular complex leads to neuronal apoptosis [26]. Second, a direct binding of HIV-Tat protein to the (LRP) 
NMDAR has been shown to cause neuronal killing [27]. Furthermore, it has been shown that NMDA receptor activation is clade dependent in that TatB protein bound to NMDA receptor, while TatC did not [28].

In sharp contrast to reports from India that showed low prevalence of $\mathrm{HAD}$, recent studies from three countries in Southern Africa where HIV-1C is the predominant clade have reported a much higher prevalence of HAD or HAND. South Africa and Botswana have reported a $25 \%$ and $38 \%$ incidence of HAD respectively [29-32], while Zambia has reported a 22\% incidence of HAND [32]. Southern Africa and Southeast Asia are the two main geographic regions where HIV-1C is prevalent. We hypothesized that the Southern African HIV-1C isolates are genetically distinct from those circulating in Southeast Asia with respect to their neuropathogenic potential. Based on previous findings that have implicated tat polymorphism as being responsible for clade differences in the incidence of HAD, we characterized HIV-1 Tat exon 1 from both geographical regions. We analyzed not only the sequences available in the databases from countries where HIV-1C is prevalent, but also the sequences derived from newly recruited patients in selected countries. We report here that tat sequences from Southern African HIV-1 isolates are genetically distinct from those in Southeast Asian countries. We also found that a greater proportion of Southern African HIV - $1 \mathrm{C}$ isolates examined (11\% to $26 \%$ ) encoded dicysteine motif $\mathrm{C} 30 \mathrm{C} 31$, whereas much lower proportions (1-3\%) of HIV-1C from Southeast Asia encoded this motif.

To determine if the higher incidence of neuropathogenesis observed in Southern Africa is due to this higher frequency of variants with dicysteine motif in Tat, we carried out functional analysis. Using both in vitro and mouse models, we compared the neuropathogenic properties of: (i) a Southern African HIV-1C isolate from Zambia with a dicysteine motif in Tat, HIV-1C 1084i [33]; (ii) a Southeast Asian isolate from India, $\mathrm{HIV}-1 \mathrm{C}_{\text {IndieC1 }}$ with a C31S substitution in Tat (iii) a HIV-1B isolate with a dicysteine motif in Tat known to cause neuronal damage and neurocognitive deficits in SCID-HIVE mouse model, HIV-1B $\mathrm{B}_{\mathrm{ADA}}$. We report that in vitro, the Southern African HIV-1C isolate, in sharp contrast to Southeast Asian HIV-1C $C_{\text {IndieC1 }}$, behaved similar to HIV-1B isolates in its robust ability to recruit monocytes, induce $\beta$ chemokines and cause apoptosis of human neurons. We also found that the increased monocyte recruitment and greater neurotoxicity of the Southern African HIV-1C isolate HIV-1C ${ }_{1084 i}$ (with a dicysteine motif in Tat) is due to Tat protein using immuno-depletion. Importantly, in the SCID HIVE mouse model, HIV-1C $\mathrm{C}_{1084 \mathrm{i}}$ caused greater neurocognitive dysfunction compared to the Southeast Asian HIV-1C IndieC1. Our study further corroborates the critical role that the Tat dicysteine motif plays in neuropathogenesis and suggests that it may be possible to use Tat genotyping to predict the neurocognitive outcomes of patients infected with HIV-1C.

\section{Results}

\section{Geographical variation in HIV-1C Tat Exon I}

Based on the higher HAD prevalence rates in several Southern African countries compared to that in India, we hypothesized that the Southern African HIV-1C isolates are genetically distinct from those circulating in Southeast Asia. To test this hypothesis, we compared the full-length HIV-1C sequences derived from selected Southeast Asian (India, China and Myanmar) and Southern African (South Africa, Zambia and Botswana) countries (Ethiopian samples could not be obtained. Thus, we have limited our studies to Southern African countries). The Southern African samples were obtained from clinics in Cape Town, South Africa and Lusaka, Zambia. The Southeast Asian samples were from Bangalore, India and Dhaka, Bangladesh. Phylogenetic analysis of full-length HIV-1C sequences revealed distinct genetic differences between HIV-1C isolates from Southern African countries and those from Southeast Asia (Figure 1A). Next, we performed population sequencing of tat exon 1 from HIV1 derived from clinical blood samples from two distinct geographical regions (Southern Africa \& Southeast Asia) where HIV-1C is the predominant clade. Our analysis indicated that the HIV-1C Tat sequences from South Africa and Zambia formed a separate cluster segregating from the Southeast Asian HIV-1C sequences from India and Bangladesh (Figure 1B). Interestingly, the most distinguishing feature of Tat sequences from South Africa and Zambia was the relatively common occurrence of variants with an intact C30C31 motif (26\% and 20\% respectively), which are rare among sequences from India and Bangladesh (3\% and 2\% respectively; Figure 2A). Previously, when Tat sequences from worldwide were analyzed as a single group, the S31 residue emerged as a signature residue for HIV-1C Tat (frequency: 0.89) [18], while for non-clade C HIV-1 Tat, C31 was a signature residue (frequency: 0.99) [18]. In order to verify that the increased frequency of CC motif is unique to HIV-1 derived from Southern Africa, we also analyzed Los Alamos database for HIV-1 Tat sequences from South Africa, Zambia, Botswana and India. These results paralleled those obtained from analyzing the clinical isolates in that the Southern African isolates exhibit a greater frequency of occurrence of C30S31 dicystine motif (Figure 2B). This striking disparity in the proportion of variants with dicysteine motif between Southern Africa and Southeast Asia broadly reflects the HAD prevalence data from these regions $[3,29,31,32,34]$. Therefore, we predicted that Southern African isolates with a C30C31 motif in HIV1 Tat are more neurovirulent. We have carried out a series of in vitro and in vivo experiments to test our prediction. 


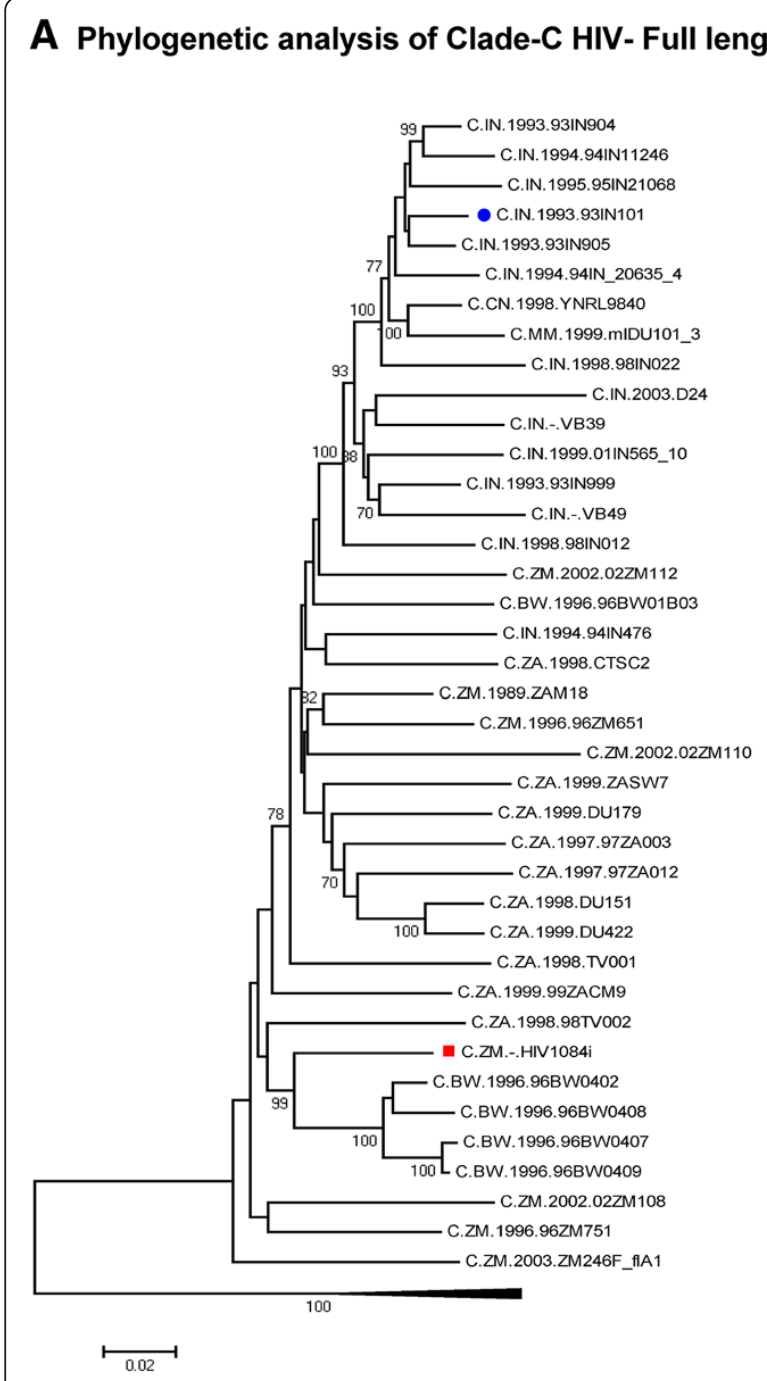

B Phylogenetic analysis of Clade-C HIV- tat

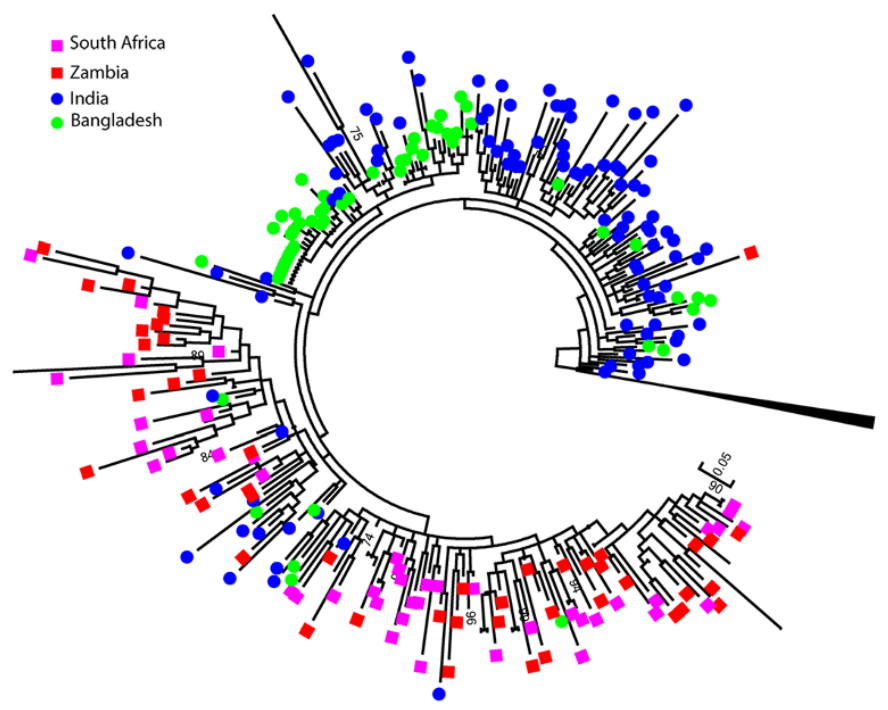

C Alignment of tat sequences employed in this study

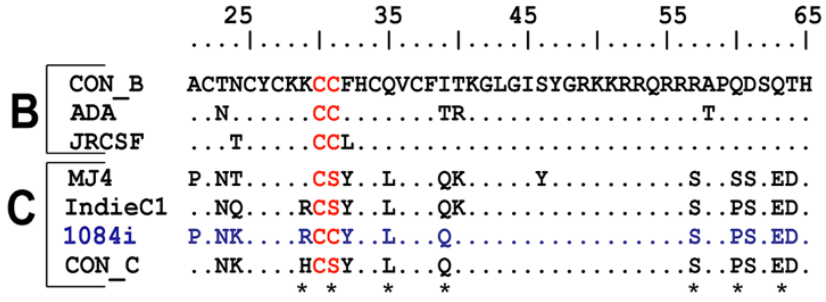

Figure 1 Phylogenetic analysis using full-length clade $\mathrm{C}$ sequences from diverse geographical locations. A. The graphic represents maximum likelihood phylogenetic tree using full - length clade C sequences from Southeast Asia (India, China and Myanmar) and Southern-Africa (South Africa, Zambia and Botswana) with reference clade B as out-group. The analysis identified a genetic divergence of HIV-1C IndieC1 (C.IN.93IN901 marked with filled Blue Circle) and HIV-1C $1084 i$ (C.ZM.HIV1084i marked with Red square) with distinct phylogenetic clusters. B. Clinical isolates from two different geographical locations (Southern-Africa and Southeast Asia; $n=250$ ) were included in the Maximum Likelihood (ML) phylogenetic tree along with the reference HIV-1C sequences from the Los Alamos database from Zambia, Botswana, South Africa and India ( $n=21)$ and HIV-1B sequences $(n=4)$ from the US, Netherlands, Thailand and France (outliers). Only the representative sequences were chosen from Los Alamos Database to avoid "cohort effect" in the phylogenetic analysis. The tree was constructed in MEGA 5 [35] software, with general time reversible with inverse gamma distribution $(G T R+G+I)$, which has been predicted as the best-fit model. The Southern African sequences are indicated by filled squares (Red: Zambia and Pink: South Africa) and Southeast Asian sequences were marked with filled circles (Green: Bangladesh and Blue: India). C. The Predicted amino acid sequence of tat gene from the Zambian HIV-1C molecular clone HIV-1 $1084 \mathrm{i}$ is

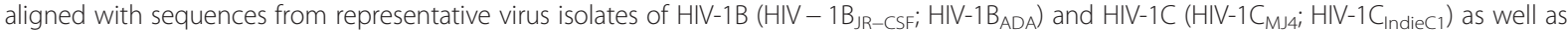
consensus sequences using ClustalW software. Clade C signature amino acid residues previously defined by Ranga et al. [18], present in the majority of HIV-1C Tat sequences in the Los Alamos database [36], are Clade C signature amino acid residues previously defined by Ranga et al. [18], present in the majority of HIV-1C Tat sequences in the Los Alamos database [36], are indicated via asterisks below consenus clade C sequence (CON_C). With the exception of C31, all these residues are conserved across all clade $\mathrm{C}$ isolates. Dots represent the residues identical with the consensus of the respective clade. Residues in red indicate C30C31/C30S31 motif in Tat. Sequences are grouped by clade and indicated on left.

\section{A Southern African HIV-1C isolate with C30C31 motif} In order to test our prediction, a replication competent Southern African HIV-1C isolate retaining a dicysteine motif would be necessary. For this purpose, we exploited a Zambian HIV-1 $1_{1084 \mathrm{i}}$ that was previously isolated from a pediatric patient. Previous analysis of this molecular clone showed that it was an intra-clade recombinant, where gag sequences clustered with Asian HIV-1C, while 

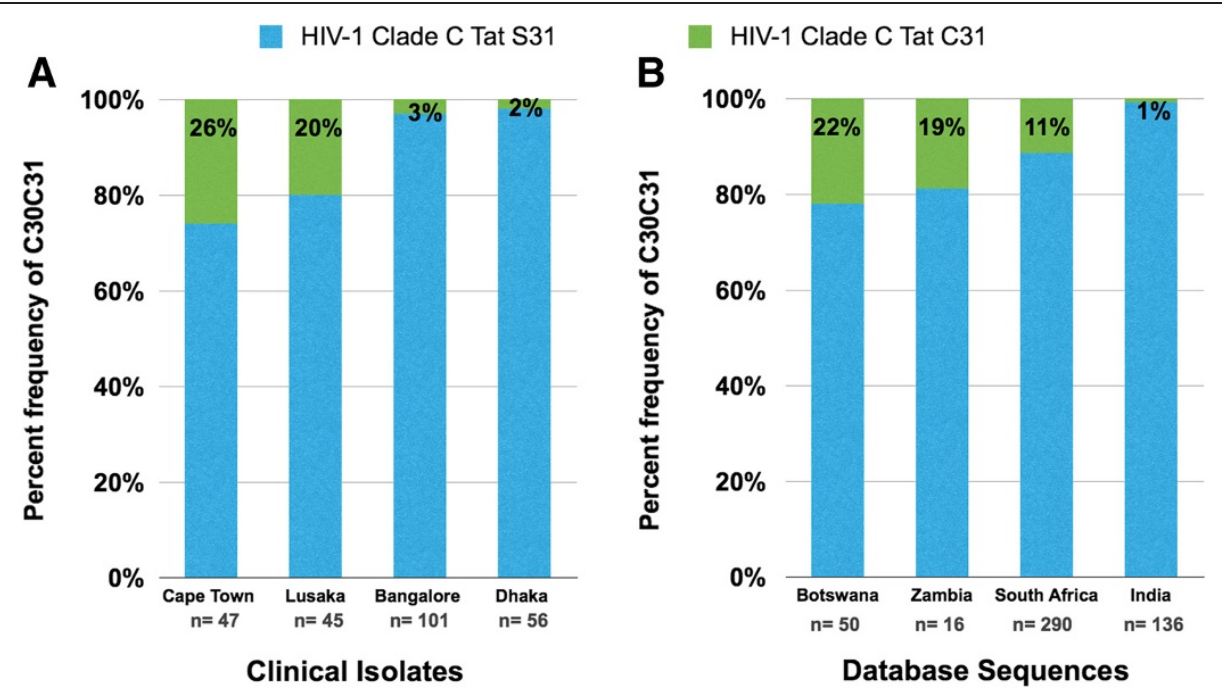

Figure 2 Geographic variation in the frequency of HIV-1C Tat CC variants. A. Frequency of HIV-1 Tat sequences with CC and CS from HIV-1-infected populations from Lusaka (Zambia), Cape Town (South Africa), Bangalore (India), and Dhaka (Bangladesh). B. Frequency of CC and CS variants in the sequence database among HIV-1 Tat sequences in countries where HIV-1C predominates. Sequences were downloaded from the Los Alamos database and aligned using Clustal-W software. Frequency of sequences with CC and CS at positions 30, 31 were calculated and plotted as stacked graphs. The numbers below the bars $(n)$ are the total independent sequences analyzed in each case.

pol and env sequences clustered with African HIV-1C [33]. Comparison with other full-length sequences from the database confirmed that it was representative of Southern African isolates (Figure 1A). In the same analysis, we included full-length HIV-1C sequences from Southeast Asia and confirmed that the Southern African isolate (HIV-1C 1084i ) was phylogenetically different from Southeast Asian isolates (Figure 1A). Further, the ClustalW alignment of the predicted amino acid sequence of HIV-1C $\mathrm{C}_{1084 \mathrm{i}}$ tat exon I [33] with the consensus HIV-1B and HIV-1C sequences and other HIV-1B and C isolates (Figure 1C) revealed that this Tat sequence retains homology to other HIV-1C Tat proteins over its entire length and it was not a recombinant. However, HIV-1 $\mathrm{C}_{1084 \mathrm{i}}$ Tat does not display the C31S polymorphism that is commonly present in HIV-1C Tat sequences. This analysis along with the fact that HIV-1C $\mathrm{C}_{1084 \mathrm{i}} \mathrm{gag}$, pol, and env sequences mapped to HIV-1C in phylogenetic analysis makes it an ideal virus to examine the neurotoxic potential of a Southern African isolate [33].

\section{Southern African HIV-1 C $_{1084 i}$ triggers increased monocyte chemotaxis compared to Southeast Asian HIV-1C isolate}

As monocyte infiltration is a hallmark of HAD, we first compared the monocyte chemotaxis properties of Southern African HIV-1C $1084 \mathrm{i}$-infected MDM supernatants with those of Southeast Asian HIV-1C and a HIV-1B isolate. In all of our studies, we have used HIV $-1 C_{1084 i}$ to represent the Southern African Tat dicysteine containing isolates, the HIV- $1 C_{\text {IndieC1 }}$ as the Indian isolate with the Tat C31S variant and the US - derived, HIV- $1 \mathrm{~B}_{\mathrm{ADA}}$ as the clade $\mathrm{B}$ virus prototype with Tat dicysteine. For monocyte migration and CCL2 induction, two additional virus isolates HIV-1B $\mathrm{B}_{\text {JR-CSF }}$ (Clade B: Tat CC) [37] and HIV-1C $\mathrm{C}_{\mathrm{MJ}}$ (Clade C: Tat CS) [38] were also used.

The five HIV isolates indicated above were employed to infect MDMs at variable inputs to match their rates of replication, propagated for a period of 5 days and the supernatants were evaluated to ensure that similar levels of p24 $(60 \mathrm{ng} / \mathrm{ml}-80 \mathrm{ng} / \mathrm{ml})$ were produced. We employed a Boyden chamber with $3 \mu$ membrane barrier and measured the ability of HIV-infected supernatants to recruit monocytes across the membrane. We found that supernatants from MDM - infected with $\mathrm{HIV}-1 \mathrm{C}_{1084 \mathrm{i}}$ attracts 2-fold more monocytes compared to HIV-1C viruses lacking the dicysteine motif ( $\mathrm{HIV}-1 \mathrm{C}_{\text {IndieCl }}$ and $\mathrm{HIV}-1 \mathrm{C}_{\mathrm{MJ} 4}$ ) $(t(6)=9.86, p<0.0001, \mathrm{n}=6)$, but less than that observed in response to HIV-1B isolates (Figures $3 \mathrm{~A}$ and $3 \mathrm{~B}$ ). HIV-1B isolates (HIV- $1 \mathrm{~B}_{\mathrm{JRCSF}}$ and HIV-1B $\mathrm{B}_{\mathrm{ADA}}$ ) attracted almost 3-fold more monocytes than HIV-1C isolates lacking dicysteine motif $(t(6)=12.61, p<0.0001, \mathrm{n}=6)$. Previously it has been established that Tat and CCL2 present in the MDM medium are responsible for increased chemotaxis caused by HIV-1B. To determine whether Tat and/or CCL2 are also responsible for increased chemotaxis induced by HIV-1 $1_{1084 \mathrm{i}}$, HIV-1 Tat and CCL2 were immuno-depleted from the medium using neutralizing antibodies and monocyte migration assays were performed [39]. Immuno-depletion of Tat resulted in the reduction in recruitment of monocytes both by HIV-1B $\mathrm{ADA}_{\mathrm{ADA}}$ and HIV$1 \mathrm{C}_{1084 \mathrm{i}}$-infected supernatants (Figure $3 \mathrm{~B}$ ). Immuno-depletion of CCL2 also decreased the number of monocytes 


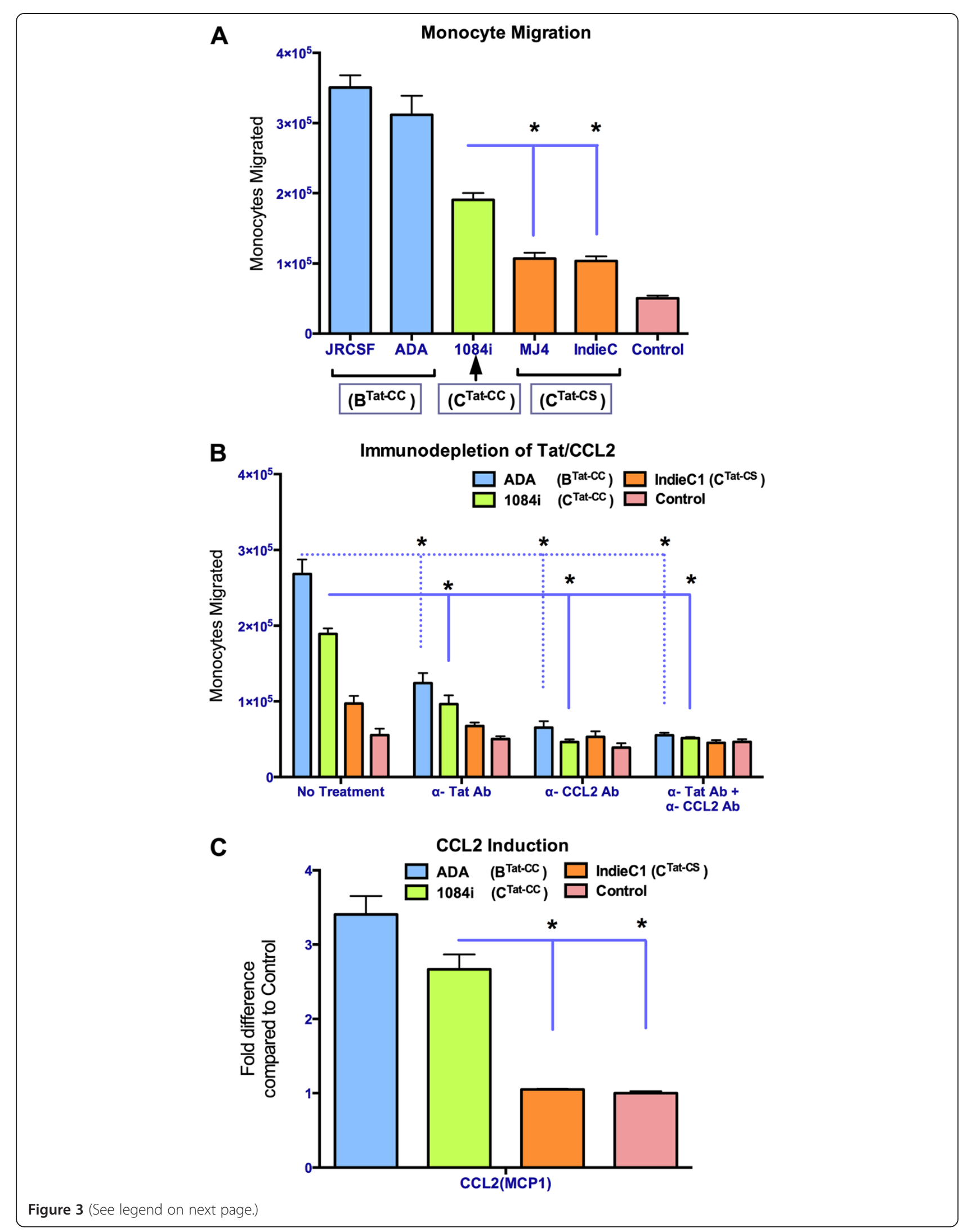


(See figure on previous page.)

Figure 3 Differential monocyte recruitment by medium from macrophages infected with different HIV-1 isolates. A. Monocyte migration caused by medium from HIV-1 infected MDMs. At least two isolate are used for each clade. HIV-1B isolates are shown in blue, HIV-1C isolates in orange and $\mathrm{HIV}-1 \mathrm{C}_{1084 i}$ in green. Southern African $\mathrm{HIV}-1 \mathrm{C}_{1084 i}$ with a dicysteine motif in Tat induces significantly higher number of monocytes to migrate compared to HIV-1C IndieC1 and HIV - 1C $\mathrm{MJ}_{4}$. Tat genotypes of each isolate are indicated in all three panels. B. Determining the soluble factors in the infected MDM supernatant responsible for monocyte migration. Immuno-depletion of Tat and CCL2 resulted in significant (*) reduction of monocyte recruitment both by HIV-1 ${ }_{\text {ADA }}$ (Clade B with dicysteine motif in Tat) and HIV-1 1084 (Clade C with dicysteine motif in Tat) infected supernatants. Serial immuno-depletion of both CCL2 and Tat did not further reduce background migration. $\mathbf{C}$. Fold increases, over uninfected macrophages, in the level of CCL2 secreted by macrophages infected with various HIV-1 isolates: HIV-1B $\mathrm{ADA}_{1} \mathrm{HIV}_{\mathrm{V}} 1 \mathrm{C}_{1084 \mathrm{i}}$ and HIV-1C IndieC1. The levels of these chemokines in the media from uninfected control MDM cells were CCL2: $20.8 \mathrm{ng} / \mathrm{ml}$. HIV-1C $1084 \mathrm{i}$ induced significantly higher levels of CCL2 induction compared to HIV-1C IndieC1 and Controls. ${ }^{*} p<0.05$.

recruited by all three viral supernatants to control levels (Figure 3B). We note that despite immuno-depletion of Tat or CCL2, there was a background level of monocyte migration. We have used low serum (2.5\%) medium for $24 \mathrm{~h}$ to reduce migration caused by chemotaxis factors present in the human serum. However, this basal level of migration, possibly caused by the presence of other $\beta$-chemokines in the serum, could not be reduced further even after serially immune-depleting both Tat and CCL2 (Figure 3B). Our results suggest that the increased migration of monocytes induced by $\mathrm{HIV}-1 \mathrm{C}_{1084 \mathrm{i}}$ is largely due to presence of Tat and CCL2 in the HIV-infected MDM medium.

We previously showed that $\mathrm{HIV}-1 \mathrm{C}_{\text {IndieC1 }}$ induces lower levels of CCL2 chemokine than HIV-1B in infected MDMs correlating to their differences in neuropathogenesis $[19,40]$. We analyzed CCL2 induction for the different HIV-1 isolates studied above. Interestingly, Southern African HIV-1C 1084 i induced 2.5-fold greater levels of CCL2 $(t(16)=10.13, p<0.0001)$ compared to uninfected controls (Control CCL2: $20.8 \mathrm{ng} / \mathrm{ml}$ ) as well as when compared to $\mathrm{HIV}-1 \mathrm{C}_{\text {IndieC1}}$, which caused no change in the induction of CCL2 $(t(16)=.3010, p>0.5)$ levels from uninfected controls (Figure $3 \mathrm{C}$ ). These results suggest that Southern African HIV-1C virus isolates with an intact dicysteine motif, similar to HIV-1B isolates, are potent inducers of chemokines, a key factor in recruitment of mononuclear phagocytes to HIV-infected sites of the brain in HAND (Figure 3C).

\section{Southern African HIV-1C 1084 i Tat protein is more neurotoxic when compared to TatC from HIV-1 $C_{\text {IndieC1 }}$} We next examined the neurotoxicity of HIV-1 $\mathrm{C}_{1084 \mathrm{i}}$ Tat when compared to HIV-1 IndieC1 TatC and TatB in vitro. Primary human neurons were treated with conditioned medium obtained from HIV-infected MDM and neuronal viability was quantified by using TUNEL assay. Immunofluorescence was used to specifically detect neurons (via staining for neurotubulin), apoptotic cells (TUNEL staining) and nuclei (DAPI staining). The neuronal viability was reduced by $60 \%$ when $\mathrm{HIV}-1 \mathrm{C}_{1084 \mathrm{i}}-$ infected MDM supernatants were used and greater than $80 \%$ when $\mathrm{HIV}-1 \mathrm{~B}_{\mathrm{ADA}}$-infected MDM supernatants were used (Figure 4A and 4B). Media from uninfected
Macrophages and $\mathrm{HIV}-1 \mathrm{C}_{\text {IndieC1}}$-infected MDMs resulted in $12 \%$ to $25 \%$ cell death respectively (Figure $4 \mathrm{~A}, 4 \mathrm{~B}$ ). In order to determine the relative contribution of Tat to neurotoxicity, the MDM supernatants were first depleted of virions and free gp120 using broadly neutralizing envelope antibodies, and subsequently Tat was immunodepleted from the medium. Neurons were exposed to virus/gp120-immunoadsorbed medium with and without immunodepletion of Tat. Neuronal apoptosis was significantly reduced upon immunodepletion of Tat from HIV-infected MDM medium (Figure 5A).

Key pathologic hallmarks of HIV associated dementia are neuronal atrophy and the loss of dendritic arbor [41]. In an in vitro setting, dendritic density, length and thickness are a proxy indicator for signs of neuronal atrophy. We chose to examine changes in dendritic thickness in response to exposure of neurons to HIV-1 conditioned medium, to evaluate neurotoxicity. We immune-depleted Tat from virus/gp120-adsorbed media and tested the effect of both virus/gp120 - adsorbed and virus/gp120- and Tat- adsorbed media on dendritic width. Analysis of the width of the neuronal processes indicated that human neurons treated with $\mathrm{HIV}-1 \mathrm{C}_{1084 \mathrm{i}^{-}}$and HIV-1B $\mathrm{BDA}_{\mathrm{ADA}}$-infected MDM supernatants depleted for both virus/gp120 and Tat proteins are significantly $\left(\mathrm{HIV}-1 \mathrm{C}_{1084 \mathrm{i}}: \mathrm{p}\right.$ value $=0.00007 ; \mathrm{HIV}-1 \mathrm{~B}_{\mathrm{ADA}}: \mathrm{p}$ value $=$ 0.0071 ) thicker than infected MDM supernatants depleted virus/gp120 (Figure 5B, 5C). We find that the dendrite width increased to match the width of untreated neurons, implicating Tat as one of the factors responsible for neuronal atrophy observed.

\section{Southern African HIV-1C $\mathrm{C}_{1084 \mathrm{i}}$ induces neurocognitive deficits in SCID mice}

The SCID HIVE is a well-characterized mouse model suitable for testing HIV-induced neurovirulence and behavioral changes $[20,21,42,43]$. We intracranially injected male SCID mice (4 groups of mice, 6 mice/group) with human uninfected MDMs as well as MDMs infected with one of the three viruses $\left(\mathrm{HIV}-1 \mathrm{~B}_{\mathrm{ADA}}, \mathrm{HIV}-1 \mathrm{C}_{\text {IndieC1 }}\right.$ or $\left.\mathrm{HIV}-1 \mathrm{C}_{1084 \mathrm{i}}\right)$. The HIV-infected cultures were verified to contain comparable levels of virus as measured by p24 in the medium. Analysis of the mouse brain samples 


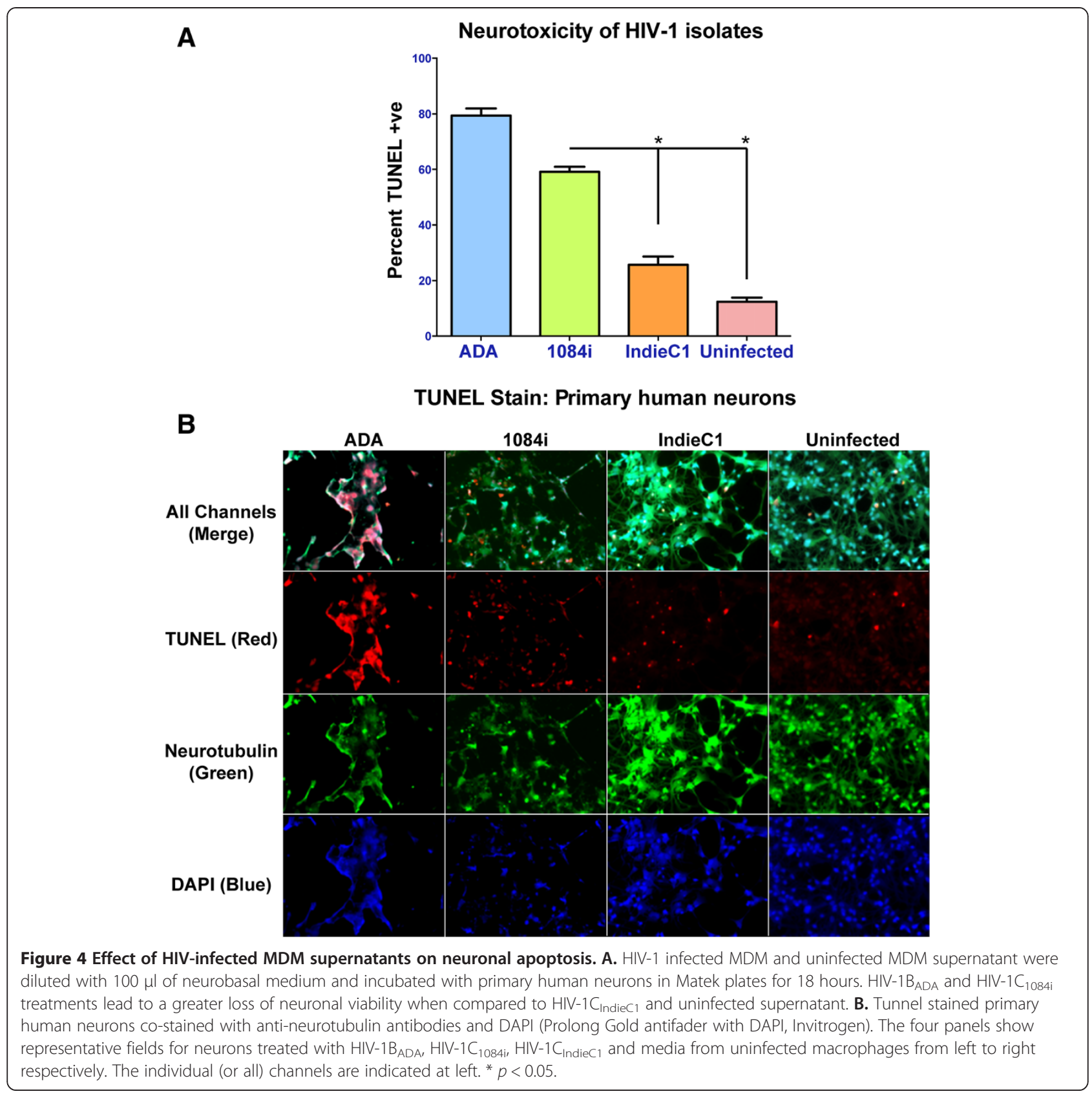

injected with the three different isolates showed a similar number of p24 infected macrophages (4-8 p24-positive cells per section) around the injection site. Cognitive assessment using the Water Radial Arm Maze (WRAM) comparing mice exposed to Southern African HIV $-1 C_{1084 \mathrm{i}}$ to those exposed to Southeast Asian $\mathrm{HIV}-1 \mathrm{C}_{\text {IndieC1 }}$ revealed the Southern African isolate affects two orthogonal measures of short term and long term working memory (working memory correct: WMC and repeat reference memory: RRM). When working memory load was highest on trial 4 during the latter most portion of testing (days 11-12 post injection), there was a significant main effect of exposure to HIV-1 isolates, HIV-1B $\mathrm{B}_{\mathrm{ADA}}$ and HIV$1 C_{1084 \mathrm{i}}$ for WMC and RRM errors (WMC $F(3,51)=5.16$, $p=0.003$; RRM $F(3,51)=7.58, p=0.0001$; Figures $6 \mathrm{~A}, 6 \mathrm{C}$, \& $6 \mathrm{D})$. The HIV-1C $\mathrm{C}_{\text {IndieC1 }}$ exposed mice did not differ from the Control group (post-hoc ps $>0.651$; Figures 6A, 6C, \& $6 \mathrm{D})$, whereas the HIV $-1 \mathrm{C}_{1084 \mathrm{i}}$ exposed mice and HIV-1B ADA exposed mice committed more errors than the Control group and $\mathrm{HIV}-1 \mathrm{C}_{\text {Indie } 1^{-}}$-exposed mice Figures $6 \mathrm{~A}, 6 \mathrm{C}$, \& 6D). Mice exposed to $\mathrm{HIV}-1 \mathrm{C}_{1084 \mathrm{i}}$, in spite of being closely related to $\mathrm{HIV}-1 \mathrm{C}_{\text {IndieC1}}$, did not differ from mice 


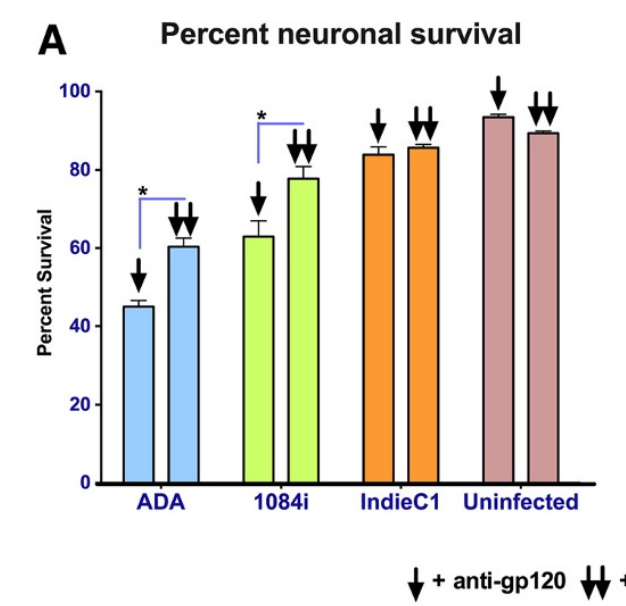

\section{B Mean dendrite width}
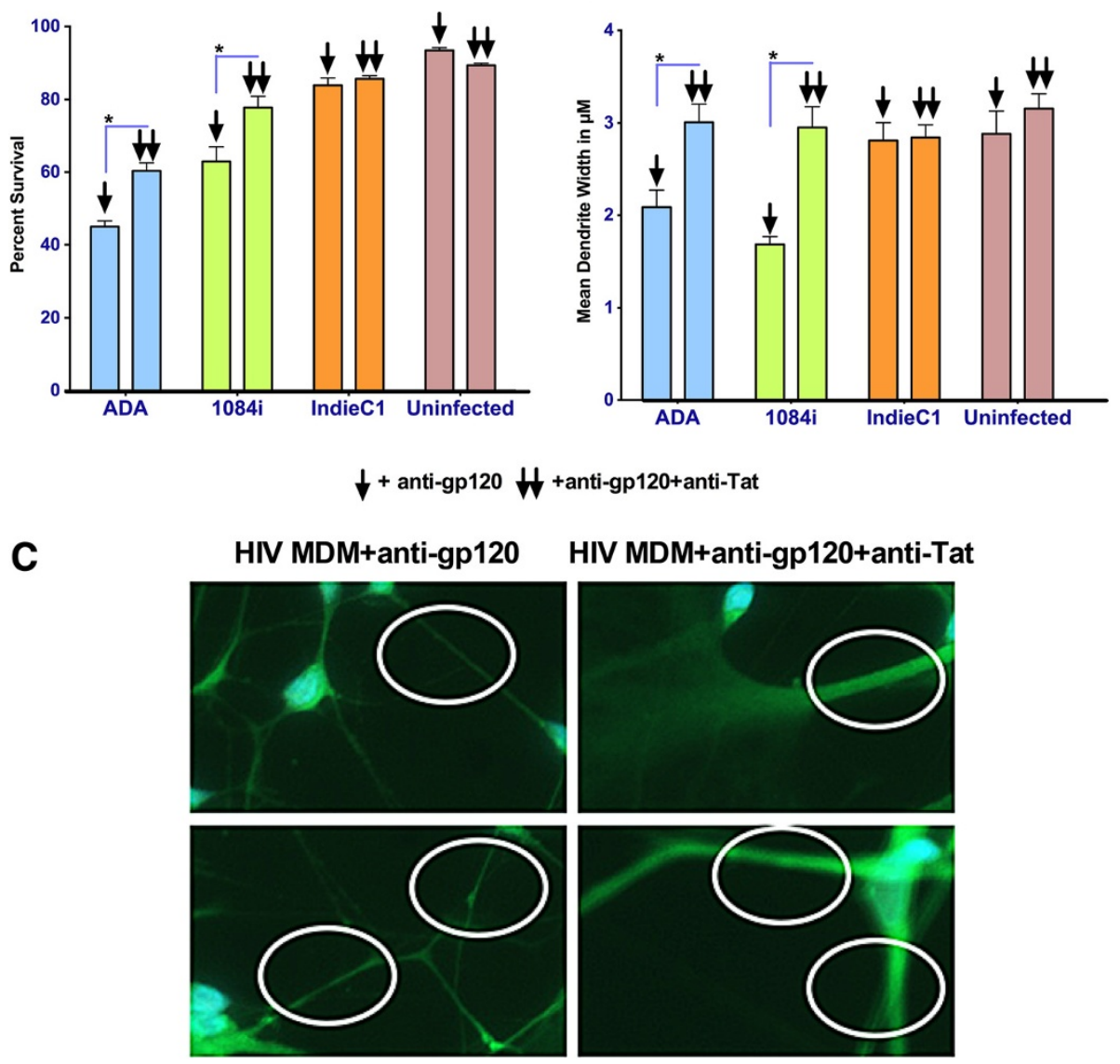

Figure 5 Neurotoxicity of Tat in HIV-1C $\mathbf{1 0 8 4 i}_{\mathbf{i}}$-infected MDM supernatant. A. HIV-infected media used in Figure 5 were used to pre-adsorb HIV particles and/or free gp120 to eliminate confounding factors and the Tat protein from such media were further adsorbed using anti-Tat

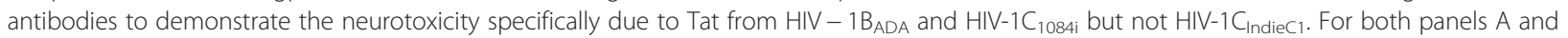
B, bars corresponding to medium depleted of virus/gp120 is shown by $\downarrow$, whereas those corresponding to medium depleted of both virus/gp120 and Tat protein are shown by $\downarrow \downarrow$. B. Measurement of dendritic width shows HIV-1B $A D A$ \& HIV-1C 1084 cause significant decreases in dendritic

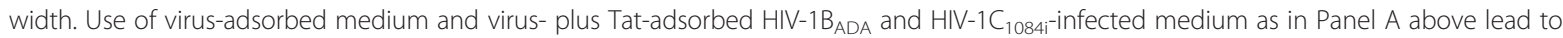

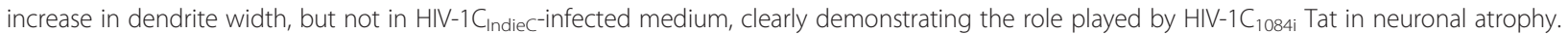
C. Representative fields showing effect of Tat immune-depletion in HIV-1C $1084 \mathrm{MDM}$ media on dendrite width. The left top and bottom panels show representative fields of primary neurons treated with $H I V-1 C_{1084 i}$ MDM media prior to Tat immuno-depletion and the right top and bottom panels show increase in dendrite width following immune-depletion of Tat. ${ }^{*} p<0.05$.

exposed to HIV-1B $\mathrm{ADA}$ (post-hoc ps >0.238; Figures 6A, $6 \mathrm{C}, \& 6 \mathrm{D})$.

On test day 13 post-injection, a $45 \mathrm{~m}$ delay was imposed between trials 2 and 3 to increase the demand placed on the working memory system of the mice. There was a significant main effect for RRM on post-delay trials 3 \& 4 $(F(3,51)=6.01, p=0.0010$; Figure $6 \mathrm{~B})$, with HIV-1C $\mathrm{C}_{1084 \mathrm{i}}$ or HIV-1B $\mathrm{B}_{\mathrm{ADA}}$ (post-hoc $p \mathrm{~s}<0.0120$ ), but not HIV-1C $\mathrm{C}_{\text {IndieC } 1}$, exposed mice committing more RRM errors as compared to the Control group (Figure 6B). For this measure, errors increased in a linear fashion from control animals, who committed no errors, to the HIV-1B $\mathrm{B}_{\mathrm{ADA}}$ exposed mice, who committed the most errors $(t(51)=4.27, p<0.0001$; Figure 6B). Our results demonstrate that exposure to Southern African HIV-1C isolate with an intact dicysteine motif in Tat causes working memory deficits similar to that caused by clade B HIV-1.

To address the strength of the relationship between each treatment group and the degree of working memory impairment, Cohen's $d$ was calculated between each group from RRM errors during test days 11-12 trials 14. The degree of working memory impairment, as compared to the Control group, increased from the clade $\mathrm{C}$ $\left(\mathrm{HIV}-1 \mathrm{C}_{\text {IndieC1 }} ; d=0.45\right)$ virus, to the clade $\mathrm{C}$ with an intact dicysteine motif $\left(\mathrm{HIV}-1 \mathrm{C}_{1084 ;} ; d=1.08\right)$ virus and the clade $\mathrm{B}\left(\mathrm{HIV}-1 \mathrm{~B}_{\mathrm{ADA}} ; d=1.53\right)$ virus demonstrating the highest degree of working memory impairment (Figures 6A, \& 6C). The HIV-1C $\mathrm{C}_{\text {IndieC1 }}$ exposed mice exhibited a lesser magnitude of working memory impairment in comparison to the HIV-1C ${ }_{1084 \mathrm{i}}(d=0.76)$ and 

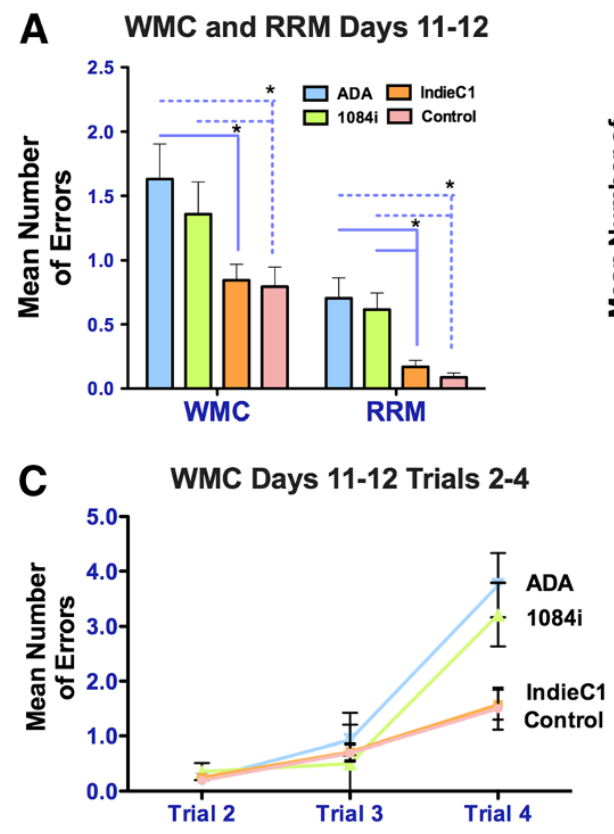

Figure 6 Cognitive performance of SCID mice exposed to HIV-1 and controls evaluated on the WRAM during the asymptotic testing phase (data represent mean \pm SE). A. Analysis of working memory errors collapsed across days 11 and 12 and trials revealed Southern African

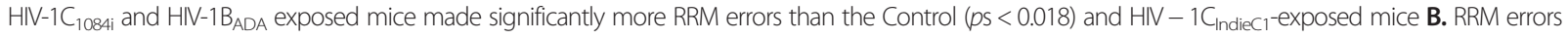

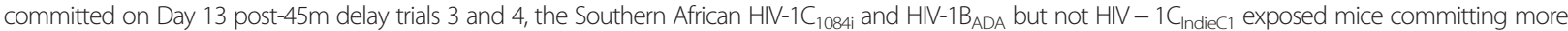
RRM errors as compared to the Control group. Group rankings for RRM errors committed on the delay followed a linear trend, with the Control group committing no errors, and the HIV-1B $\mathrm{B}_{\mathrm{ADA}}$ group committing the most. C. Analysis of Working Memory Correct errors committed on trial 4, when working memory load was the highest HIV-1C IndieC1 exposed mice did not differ from the Control group, but the Southern African HIV-1C $1084 i$ and HIV-1 $B_{A D A}$ exposed mice committed more errors. ${ }^{*} p<0.05 ; \wedge p<0.05$ linear trend. D.Evaluation of Reference Memory Repeat errors committed on trial 4 , the $H I V-1 C_{1084 i}$ and

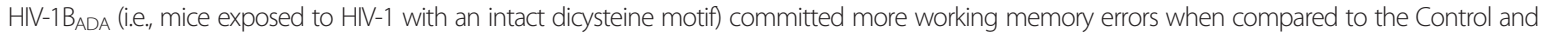
HIV-1 IndieC1 (clade C HIV-1 with C31S substitution in Tat) groups.

HIV- $1_{\text {ADA }}$ exposed mice $(d=1.29)$, and that the magnitudes of working memory impairment between the HIV-1 $\mathrm{C}_{1084 \mathrm{i}}$ and $\mathrm{HIV}-1 \mathrm{~B}_{\mathrm{ADA}}$ exposed mice were similar $(d=0.13$; Figures 6A, \& 6C).

\section{Discussion}

We report that tat gene in the HIV-1 clade C isolates circulating in Southern African countries (South Africa, Zambia and Botswana) is evolutionarily distinct from those in Southeast Asia (India and Bangladesh). Southern African HIV-1C isolates displayed a uniquely higher proportion of variants encoding Tat protein with a dicysteine motif (C30C31) when compared to those in Southeast Asian countries. The interesting correlation between the proportion of viruses encoding Tat with a dicysteine motif and the higher prevalence of HAD in these countries [29-32] prompted us to examine the hypothesis that the presence of a dicysteine motif in clade $C$ Tat is a determinant of neuropathogenesis. Evidence presented in this communication includes neurocognitive data in SCID-HIVE model as well as in vitro studies showing that a Southern African variant HIV-1C isolate (HIV - $1_{1084 i}$ ) containing a dicysteine motif in Tat displays a robust ability to both recruit monocytes and to cause neurotoxicity.
Previous studies examining HIV-1 env sequences from Northeast India have concluded that Indian clade $C$ has evolved into a distinct sub-clade termed $C_{I N}$ [44]. More recently, Neogi et al. [45] analyzed 168 HIV sequences drawn from 4 distinct regions of India, systematically analyzed gag, pol and env regions and concluded that the Indian clade $\mathrm{C}$ HIV has evolved independently from African clade C HIV over the last 40 years. They dated the origin of the Indian clade $\mathrm{C}$ via the most recent common ancestor (tMRCA) analysis and compared it to tMRCAs determined for clade C HIV circulating in other countries (Ethiopia, Zimbabwe and Brazil). This analysis led them to conclude that the Indian clade $\mathrm{C}$ probably originated from the African clade $C$, but has evolved independently with little intermixing with African clade $\mathrm{C}$ sequences $[45,46]$. It is generally thought that the region-specific evolution of HIV-1 clades is likely due to founder effects [44] although one cannot rule out the role of host genetic factors in perpetuating specific variants in that region [47].

The cysteine-rich domain is crucial for monocyte chemotaxis function of HIV-1B Tat protein [8] as is the case for $\beta$-chemokines [48]. The absence of dicysteine motif in HIV-1C Tat is shown to be responsible for the 
reduced chemotactic function [18]. Comparison of HIV1B and HIV-1C Tat proteins showed that B Tat induces robust monocyte migration and causes the induction of chemokines, such as CCL2, while HIV-1C Tat has only a weak activity for both these properties [19]. Although it is formally possible that clade differences may be due to differential secretion or accumulation of Tat in the HIVinfected MDM medium for these two clades of HIV, we believe this to be unlikely. Li et al. [28] have previously reported that cells transfected with HIV-1C and HIV-1B Tat expression constructs secreted similar levels of Tat proteins. Furthermore, using chemically synthesized Tat proteins, Campbell et al. [22] showed that a HIV-1B Tat protein binds to CCR2, induces intracellular calcium flux, causes monocyte chemotaxis as well as induces CCL2 and TNF $\alpha$, while Tat from a Southeast Asian HIV-1C (without a dicysteine motif) did not. The same group showed that Tat protein from a Southern African HIV-1C isolate (Botswanan) retaining a dicysteine motif was competent for monocyte chemotaxis and induced CCL2 and TNF $\alpha$ at levels similar to HIV-1B Tat protein [22]. In addition, a Southeast Asian patient isolate from Bangalore encoding a Tat protein with an intact dicysteine motif also displayed a phenotype similar to similar to Southern African HIV-1 $1_{1084 \mathrm{i}}$ (Additional file 1: Figure S1).

The use of HIV-1C 1084 , a HIV-1C isolate from Zambia, allowed us to confirm the hypothesis that the Southern African dicysteine motif-containing HIV-1C isolates are more neuropathogenic [33]. Despite the short time span of SCID-HIVE model (4 weeks), the features exhibited in this model (gliosis, neuronal atrophy and neurocognitive deficits) are consistent with chronic encephalitis rather than an acute inflammatory state $[20,21,42,43]$. This model simulates the loss of memory and cognitive dysfunction observed in patients suffering from HAD/HAND and provides an effective means to compare the effects of different virus isolates [19]. The cognitive tests in mice suggest that HIV- $1 \mathrm{C}_{1084 \mathrm{i}}$ isolate, by virtue of encoding a Tat protein with an intact dicysteine motif, can be as neurotoxic as HIV-1B viruses. Dicysteine motif of HIV-1 Tat has also been shown to be critical for direct neurotoxicity $[7,28]$. Thus, in vitro data showing direct neurotoxicity of HIV-1 $C_{1084 i}-$ infected MDM supernatants and SCID-HIVE data showing neurocognitive defects caused by $\mathrm{HIV}_{1084 \mathrm{i}}$ together support the key role played by the dicysteine motif in HIV neuropathogenesis.

Previous studies have shown that MDMs, either infected with HIV-1B [19] or exposed to purified recombinant Tat protein from HIV-1B $[19,23,25]$, lead to a greater level of induction of inflammatory chemokines such as CCL2 than HIV-1C or Tat protein derived from it. $\beta$-chemokine levels are elevated in cerebrospinal fluid of patients with HAD [49] and HIV-1 Tat is one of the key viral proteins responsible for the induction of such chemokines [10]. Our present study showed that when an intact dicysteine motif is present in Tat (HIV-1C $1084 \mathrm{i})$, a HIV-1C virus isolate is able to induce CCL2 in sharp contrast to clade $\mathrm{C}$ isolates lacking the dicysteine motif $\left(\mathrm{HIV}-1 \mathrm{C}_{\text {IndieC1 }}\right)$. Our results suggest that the intact dicysteine motif is critical for the induction of inflammatory chemokines that play a crucial role in development of $\mathrm{HAD} / \mathrm{HAND}$.

Earlier studies led to the idea that some clades of HIV-1, such as clade $C$, cause reduced neuropathogenesis $[3,4]$. Our current results highlight the fact that all clade C HIV isolates do not display a C30S31 polymorphism in the Tat protein encoded by them. Furthermore, the presence of variant clade $C$ viruses with a C30C31 dicysteine motif can be endowed with capacity to cause neuropathogenesis. It is important to recognize that even though $99 \%$ of clade $\mathrm{B}$ isolates display C30C31 motif, HAD is observed in only a third of the HIV-1B-infected individuals. A broad interpretation of our current finding is that all clade $\mathrm{C}$ variants bearing Tat with C30C31 dicysteine motif are neurovirulent. If this notion is true, although unproven currently, it would suggest that unlike clade $\mathrm{B}$, clade $\mathrm{C}$ virus may contain other determinants outside of tat gene, that when combined with the C30C31 motif, increase neurovirulence. Additional studies would be necessary to delineate the relative roles of Tat dicysteine motif and other potential neurovirulent signatures elsewhere on the Southern African subtype $C$ isolates. One limitation of our study is that our SCID-HIVE experiments were conducted using single isolates for each of the three classes examined. This limitation will be overcome as more of well-characterized African isolates with an intact C30C31 become available. However, our conclusions are strongly supported by multiple lines of evidence from various laboratories supporting the view that the C30C31 plays multiple key roles in neuropathogenesis (monocyte infiltration, neurotoxicity and induction of proinflammatory cytokines) $[8,18,19,22-25,28,50]$. Based on the findings reported here, it may be possible to predict the neurocognitive outcomes for individuals newly infected with HIV-1 clade $\mathrm{C}$ by determining the presence of $\mathrm{C} 30 \mathrm{C} 31$ in tat gene. In order to clinically validate our findings, it is necessary to conduct systematic studies in countries where HIV-1C is the dominant clade, by screening infected individuals for the presence of C30C31 versus C30S31 followed by examining their neurocognitive deficits to determine HAD.

\section{Conclusions}

Our results demonstrate that HIV-1C isolates from Southern African countries are genetically distinct from those circulating in Southeast Asia. A greater proportion of viruses in Southern Africa display the neuropathogenesisassociated dicysteine motif in HIV Tat protein resulting in a large disparity in HIV associated neurocognitive disease 
in different areas of the world. Southern African isolates with HIV-1 Tat displaying dicysteine motif show more robust monocyte migration, neurotoxicity and cognitive deficits in a SCID-HIVE model than Southeast Asian HIV$1 \mathrm{C}$ isolates. We propose that it is possible to predict the neurocognitive outcome in millions of HIV-1C infected individuals by genotyping the HIV-1 Tat gene. Longitudinal HIV-1 cohort studies in Southern Africa and Southeast Asia with neuropsychiatric evaluations are required to further substantiate our conclusions.

\section{Methods}

\section{Primary neurons and HIV isolates}

Primary neurons were isolated and cultured as described earlier [51]. Centrifugally elutriated human monocytes were purchased from University of Nebrasaka Medical center. The monocytes were differentiated into macrophages by culturing in MCSF and 10\% Human serum for a period of 7 days.

HIV-1 isolates employed for our in vitro and mouse model studies, HIV-1 $1_{\text {ADA }}$ (US clade B), HIV-1 IndieC1 $_{\text {I }}$ (Indian clade C isolate) and HIV-1 $1_{1084 \mathrm{i}}$ (Zambian clade C) were generated by transfection of molecular clone DNA into $293 \mathrm{~T}$ cells and the virus released was quantitated by p24 Enzyme-linked immune-sorbent assay (ELISA; Applied Biosystems, Inc). In experiments to measure monocyte migration, two additional virus isolates HIV-1B $\mathrm{B}_{\text {IR-CSF }}$ (Clade B: Tat CC) [37] and HIV-1C $\mathrm{CJJ}_{4}$ (Clade C: Tat CS) [38] were also used [19,39].

\section{Sequence analyses, population studies and alignments Study population}

HIV-1-infected patient samples analyzed were from Cape Town, South Africa; Lusaka, Zambia; Bangalore, India and Dhaka, Bangladesh. In Bangalore and Dhaka, new studies were initiated while pre-existing patient samples in Cape Town and Lusaka were used to obtain tat sequences for our analysis. Ethical approval for this study was obtained from the Einstein Institutional Review Board (IRB) as well as from all local IRBs. See Additional file 2: Table S1 for patient demographics.

\section{Full length sequence analysis}

Full-length HIV-1C sequences derived from Southeast Asian (India, China and Myanmar) and Southern African (South Africa, Zambia and Botswana) countries where HIV-1C is the predominant clade were obtained along with Subtype B reference sequences from the Los Alamos HIV-1 database. The sequences were aligned using Clustal-W2. Maximum likelihood phylogenetic tree was constructed based on General Time reversible model with representative sequences. Phylogenetic analyses were conducted in MEGA5 [35].

\section{Generating and analyzing of HIV-1 Tat sequences}

For genotyping tat, whole blood was drawn from infected patients. Genomic DNA was isolated from either peripheral blood mononuclear cells or from whole blood and HIV-1 clade was determined based on gag and env sequencing using Maximum Likelihood (ML) phylogenetic tree in Molecular Evolutionary Genetics Analysis version 5 (MEGA5) [35]. HIV-1 tat exon 1 was PCR amplified from genomic DNA using primer sequences shown in Additional file 3: Table S2. Sequencing was via primers located well upstream of Exon 1 (nucleotide 5781 from HxB2 reference clone). The PCR primers were designed to amplify the entire tat exon 1 from the $3^{\prime}$ end of the $v p r$ (HXB2 position 5781) up to the $5^{\prime}$ end of $v p u$ (HXB2 terminal position 6242), with the tat exon 1 lying between HXB2 position 5831 and 6045). Thus, the amplicon has a region of 50 nucleotides upstream and 200 nucleotides downstream of the tat exon 1 sequence. All study sequences were screened for PCR cross-contamination using neighbor joining phylogenetic tree. All study sequences demonstrated well-separated branches, indicating the absence of cross-contamination. After excluding partial and problematic sequences, the percent frequency of sequences with intact dicysteine motifs was determined. The data were plotted using Graphpad Prism (v5.1, GraphPad Software, La Jolla, CA).

HIV-1 tat sequences that were already available prior to our study were obtained from the Los Alamos database from countries where HIV-1C was the most prevalent clade. Tat amino acid sequences were generated by translation were aligned using Clustal-W2 [52]. Sequences with premature stop codons in its open reading frame (ORF) and frame-shifts were excluded. Total numbers of HIV-1C Tat sequences with intact dicysteine motifs were enumerated and percentages derived.

\section{HIV-1 Infection of MDMs}

Elutriated primary human monocytes (University of Nebraska Medical Center) were differentiated into macrophages and infected with HIV-1B $\mathrm{B}_{\mathrm{ADA}}$ [53], HIV $-1 \mathrm{C}_{\text {IndieC1 }}$ [54] or with HIV-1C 1084i [33] and propagated for a period of 14 days as described previously [19]. A comparable level of virus production was achieved among different viruses as described previously by varying the multiplicity of infection to achieve similar levels of virions in the medium following 14-day propagation. Equivalence of virus levels between the cultures was determined by p24 staining of infected MDMs [19,39] and by measuring the p24 levels in the medium.

\section{Monocyte migration studies and CCL2 induction Monocyte migration}

Human MDMs were cultured for $5 \mathrm{~d}$ under the same conditions as described above. Approximately $2 \times 10^{5}$ MDMs were plated in the lower wells of a 24-well plate 
[19,39]. MDMs were infected with HIV-1 $1_{\text {ADA }}$ (clade B) at an MOI of 0.1 for $1 \mathrm{~h}, \mathrm{HIV}-1_{\text {Indie-C1 }}$ (clade $\mathrm{C}$ with C31S substitution in Tat) at an MOI of 0.01 for $3 \mathrm{~h}$ and HIV-11084i (clade $\mathrm{C}$ with dicysteine in Tat) at an MOI of 0.1 for JRCSF, and a MOI of 1 for MJ4 for $5 \mathrm{~d}$. ELISA for $\mathrm{p} 24$ in the supernatants showed equal viral loads (60 ng/ml to $80 \mathrm{ng} / \mathrm{ml} \mathrm{p24)} \mathrm{for} \mathrm{all} \mathrm{viruses.} \mathrm{Three} \mathrm{hundred}$ microliters of HIV-1 infected MDM supernatant was added to the bottom chamber and 500,000 monocytes were added to the transwell. The number of monocytes migrated were analyzed after 24 hours by counting the cells in the bottom chamber using a hemocytometer. The bottom well is treated with Accutase (Millipore) prior to resuspending the cells from the bottom chamber to ensure there are no adherent monocytes that are missed.

\section{Tat and CCL2 immuno-depletion}

Tat and CCL2 were immunodepleted from HIV-1 infected MDM supernatants using either anti-Tat (E 1.1; [50]) or anti-CCL2 antibodies (MAb 279; R\&D systems) as described [19,39]. For this purpose anti-Tat and antiCCL2 antibodies were bound to Pansorbin beads (Calbiochem, Cat no. 507861) on ice for an hour. After incubation of the antibodies with the beads (Pansorbin) the beads are centrifuged and resuspended in a small volume, $25 \mu \mathrm{l}$, and added to the conditioned medium obtained from the HIV-infected MDM. Following incubation for an hour, the beads are pelleted and the supernatant, without the beads, are used for the migration assay as described above.

\section{Measurement of CCL2}

CCL2/MCP-1 levels were measured using an ELISA kit from Invitrogen (MCP-1 Human ELISA Kit- KHC 1011) in HIV-1-infected MDM supernatants collected on day 14 from five different virus isolates and from uninfected MDMs. On Day 13, MDMs were incubated for $24 \mathrm{~h}$ in fresh medium without human serum to eliminate the contribution of CCL2 in human serum. The day 15 noserum supernatant was collected, and ELISA for CCL2 ( $R \& D$ Systems) was performed in triplicates in three separate experiments [19].

\section{Neurotoxicity}

Primary human neurons were isolated and cultured as described earlier [51]. Approximately 100,000 primary neurons were plated on coated MatTek well plates for a period of 2 days and allowed to stabilize and differentiate. HIV-1 infected MDM (HIV-1B $\mathrm{BDA}_{\mathrm{ADA}}(14.8 \mathrm{ng} / \mathrm{ml})$, HIV-1C IndieC $\left.(16.2 \mathrm{ng} / \mathrm{ml}), \mathrm{HIV}-1 \mathrm{C}_{1084 \mathrm{i}}(15.7 \mathrm{ng} / \mathrm{ml})\right)$ \& the uninfected MDM supernatant $(100 \mu \mathrm{l})$ were diluted with $100 \mu \mathrm{l}$ of Neurobasal medium (Gibco) and then added to primary Neurons. Following incubation for 18 hours at $37^{\circ} \mathrm{C}$, neurons were fixed and TUNEL assay was performed using the TMR in situ hybridization kit (Roche; Cat No. 12156792910). Neurons were also stained using anti-neurotubulin antibodies (Abcam cat. No. 21058) and 4',6-diamidino-2-phenylindole (DAPI; Prolong gold anti-fade agent with DAPI, Invitrogen, cat number, p36931) to distinguish them from astrocytes. Image capture and analysis was done using Nikon (NIS elements) advanced research software. Percent apoptosis/survival was determined based on the proportion of cells with DAPI stain that were TUNEL-positive. Dendrite width was measured using Nikon (NIS elements) advanced research software and median dendrite width was calculated using GraphPad Prism (v5.1, GraphPad Software, La Jolla, CA).

\section{SCID HIVE mouse model}

\section{Intracranial injection of HIV-infected MDMs}

HIV-infected MDMs prepared as described above were employed for intracranial injection. At the end of a 14-day in vitro propagation of MDMs, prior to intracranial injection, the p24 levels in the supernatants of MDMs infected with HIV-1B $\mathrm{B}_{\mathrm{ADA}}, \mathrm{HIV}-1 \mathrm{C}_{1084 \mathrm{i}}$ and HIV-1C $\mathrm{C}_{\text {IndieC1 }}$ were $76.6 \mathrm{ng} / \mathrm{ml}, 63.8 \mathrm{ng} / \mathrm{ml}$ and $78.9 \mathrm{ng} / \mathrm{ml}$ respectively. Approximately $10^{5}$ MDMs, uninfected or infected with one of the three viruses were injected intracranially (i.c.) into 4-week old B6.CB17-Prkdc SCID/Szj male mice (Jackson Laboratories) as before $[19,55]$. Upon analyzing the mouse brain samples injected with the three different isolates, they too exhibited a similar number of HIVinfected macrophages (4-8 p24-positive cells per section) around the injection site.

\section{Cognitive assessment of mice}

Twenty-four male mice (B6.CB17-Prkdc SCID/Szj) were injected with MDMs (i.e., $6 \mathrm{HIV}-1 \mathrm{C}_{1084 \mathrm{i}}, 6 \mathrm{HIV}-1 \mathrm{~B}_{\mathrm{ADA}}$, $6 \mathrm{HIV}-1 \mathrm{C}_{\text {IndieC1 }}$ and 6 control, uninfected MDMs). Following the i.c. injection of MDMs, mice were allowed to recover for 5 days followed by testing using win-shift Water Radial Arm Maze (WRAM) as previously described [19]. The win-shift WRAM utilizes water escape onto hidden platforms as the reinforcer [19,55-57]. The testing protocol included an asymptotic phase (days 11-12) used for statistical analysis [56,58]. Working memory correct (WMC) errors were defined as entries into an arm wherein a platform had already been located, reference memory (RM) errors were an initial entry into an arm that never contained a platform, and reference memory repeat (RRM) errors were repeat entries into an arm that never contained a platform and were all quantified based on Jarrard and colleagues' [59] orthogonal measures. On day 13, a 45 minute delay was imposed between trials 2 and 3 to assess retention of multiple items of spatial information [60]. The dependent measures for performance on the delay day were total WMC, RRM, and RM errors on trials 3 and 4, for trials after the 45 minute delay. 


\section{Statistical analysis}

Statistical analysis for the in-vitro studies was performed using Grouped Analysis and plotted in Graphpad Prism 5.1. For WRAM studies, data were analyzed using an omnibus mixed model ANOVA with Treatment as the between variable, and Days and/or Trials as the within variable(s). Follow-up comparisons employed Fisher protected least squares difference (PLSD) post-hoc tests when a significant omnibus ANOVA was found. Using SPSS (version 18, IBM, Somers, NY), polynomial contrasts were employed to assess trends in the data between treatment groups and errors committed on the WRAM. Cohen's $d$ was calculated for specific pairwise comparisons between the HIV-infected groups and the control group. Cohen's $d$ was employed as a measure of effect size that assesses the difference between two group means represented in standard deviation units [61].

\section{Endnote}

Sequences generated for this manuscript have been deposited in Genbank. The accession numbers are: India- JQ241040-JQ241062 and JQ241064 - JQ241139; Zambia- JX661510-JX661554; Bangladesh- JX675467JX675522; South Africa- JX675523- JX675569.

\section{Additional files}

Additional file 1: Figure S1. A new isolate of HIV-1 $\mathrm{C}^{\text {TatCC }}$ behaves similar to HIV-1 $1_{1084 i}$ in stimulating monocyte migration and CCL2 release. A. Monocyte migration caused by medium from HIV-1 infected PBMCs. Southern African HIV-1C 1084i $_{\text {and Indian HIV-1C }}$ IN1290s motif in Tat induce higher number of monocytes to migrate compared to HIV-1C IndieC1 and Control. B. Fold increases, over uninfected PBMCs (which produced $1 \mathrm{ng} / \mathrm{ml}$ ), in the levels of CCL2 secreted by PBMCs

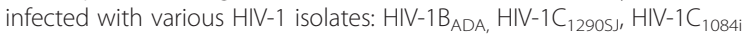
and HIV-1C IndieC1. $_{\text {. HIV-1C }}$ 1084i and HIV-1C $C_{1290 s}$ induced higher levels of CCL2 release compared to HIV-1C $C_{\text {Indiec1 }}$ and Controls. $p$ values indicated in panels A and B were calculated using Fisher's PSLD test.

Additional file 2: Table S1. Patient demographics and clinical status. Additional file 3: Table S2. Tat primers used in analysis of patient samples.

\section{Abbreviations}

HIV-1: Human immunodeficiency virus type 1; HAND: HIV associated neurocognitive disorders; HAD: HIV associated dementia; MND: Minor neurocognitive disorders; SCID: Severe combined immune deficiency; HIVE: HIV encephalitis; WMC: Working memory errors; RRM: Repeat reference memory; MDM: Monocyte derived macrophages; ELISA: Enzyme-linked immune-sorbent assay.

\section{Competing interests}

The authors declare that they have no competing interests.

\section{Authors' contributions}

VRR generated viruses and virus infected cells, conducted all in vitro tests, performed cognitive studies and drafted the manuscript; UN conducted all sequence analysis; JST carried out the statistical analysis for the cognitive testing; LP helped conduct a key aspect of cognitive test; MR generated Bangladeshi sequences; CF-F helped with the cognitive testing; SG generated the Zambian tat sequences; RMR generated the Zambian HIV-1C 1084i Clone from HIV-1C 1084 viral isolates obtained by CW and SG; UR supervised the isolation of the HIV $V_{S}$ clone and provided the anti-Tat antibody E1.1; TA designed the cross-sectional study for Bangladesh; JJ designed the cross-sectional study for South Africa and provided the Tat sequences; EE isolated human primary neurons and provided expertise in measuring neuronal apoptosis; AS designed the cross-sectional study for India; HB-N helped design the cognitive testing and helped draft the manuscript; WRT designed the overall cognitive testing, supervised the cognitive testing and helped draft the manuscript; VRP designed the overall study, supervised all in vitro tests, conceived and initiated the cross - sectional studies, initiated and coordinated the collaborative effort and helped draft the manuscript. All authors read and approved the final manuscript.

\section{Acknowledgements}

This work was mainly supported by NIH R01 MH083579 (V.R.P.) and NIH D43 TW001403 (V.R.P.). The work was also supported by NIH P01 Al048240 (R.M.R.), NIH NS74903 \& NIH GM103509 (to C.W.), NIH R01 MH096625 (to E.E.) and NIH T32 Al060547 (to S.G.). The authors wish to thank the Einstein/ Montefiore Center for AIDS Research (P30 Al051519) for the use of BSL3/ Clinical Virology Core services; Jasmeen Dara and Arthur Ruiz for reading the manuscript, Milka Rodriguez and Jayashree Nandi for technical assistance and Susan Engelbrecht for help with sequencing the Cape Town samples.

\section{Author details}

${ }^{1}$ Department of Microbiology and Immunology, Albert Einstein College of Medicine, 1300 Morris Park Avenue, Bronx, NY 10461, USA. Division of Clinical Virology, Department of Microbiology and Pediatrics, St. John's Medical College and Hospital, Sarjapur Road, Bangalore, India. ${ }^{3}$ Department of Psychology, Arizona State University, Tempe, AZ, USA. ${ }^{4}$ Arizona Alzheimer's Consortium, Phoenix, AZ, USA. ${ }^{5}$ Atlanta VA Medical Center, Decatur, GA, USA. ${ }^{6}$ International Centre for Diarrhoeal Disease Research, Mohakhali, Dhaka, Bangladesh. ${ }^{7}$ Immunology and Molecular Pathology Program Emory University, Graduate Division of Biological and Biomedical Sciences, Atlanta, GA, USA. ${ }^{8}$ Nebraska Center for Virology and the School of Biological Sciences, University of Nebraska-Lincoln, Lincoln, NE, USA. ${ }^{\circ}$ Dana-Farber Cancer Institute and Harvard Medical School, Boston, MA, USA. ${ }^{10}$ Jawaharlal Nehru Centre for Advanced Scientific Research, Bangalore, India.

${ }^{11}$ Department of Psychiatry and Mental Health, University of Cape Town, Cape Town, South Africa. ${ }^{12}$ Public Health Research Institute (PHRI), Newark, NJ, USA. ${ }^{13}$ Department of Microbiology and Molecular Genetics, UMDNJ, Newark, NJ, USA. ${ }^{14}$ Department of Neurology, Emory University School of Medicine, Atlanta, GA, USA.

Received: 3 August 2012 Accepted: 28 May 2013

Published: 8 June 2013

\section{References}

1. Antinori A, Arendt G, Becker JT, Brew BJ, Byrd DA, Cherner M, Clifford DB, Cinque $P$, Epstein LG, Goodkin K, et al: Updated research nosology for HIV-associated neurocognitive disorders. Neurology 2007, 69:1789-1799.

2. Geretti AM: HIV-1 subtypes: epidemiology and significance for HIV management. Curr Opin Infect Dis 2006, 19:1-7.

3. Satishchandra P, Nalini A, Gourie-Devi M, Khanna N, Santosh V, Ravi V, Desai A, Chandramuki A, Jayakumar PN, Shankar SK: Profile of neurologic disorders associated with HIV/AIDS from Bangalore, south India (1989-96). Indian J Med Res 2000, 111:14-23.

4. Clifford DB, Mitike MT, Mekonnen Y, Zhang J, Zenebe G, Melaku Z, Zewde A, Gessesse N, Wolday D, Messele T, et al: Neurological evaluation of untreated human immunodeficiency virus infected adults in Ethiopia. J Neurovirol 2007, 13:67-72.

5. Langford TD, Letendre SL, Larrea GJ, Masliah E: Changing patterns in the neuropathogenesis of HIV during the HAART era. Brain Pathol 2003, 13:195-210.

6. Sacktor N, Lyles RH, Skolasky R, Kleeberger C, Selnes OA, Miller EN, Becker JT, Cohen B, McArthur JC: HIV-associated neurologic disease incidence changes: multicenter AIDS cohort study, 1990-1998. Neurology 2001, 56:257-260

7. Li W, Galey D, Mattson MP, Nath A: Molecular and cellular mechanisms of neuronal cell death in HIV dementia. Neurotox Res 2005, 8:119-134. 
8. Albini A, Benelli R, Giunciuglio D, Cai T, Mariani G, Ferrini S, Noonan DM: Identification of a novel domain of HIV tat involved in monocyte chemotaxis. J Biol Chem 1998, 273:15895-15900.

9. Beall CJ, Mahajan S, Kuhn DE, Kolattukudy PE: Site-directed mutagenesis of monocyte chemoattractant protein-1 identifies two regions of the polypeptide essential for biological activity. Biochem J 1996, 313(Pt 2):633-640.

10. Conant K, Garzino-Demo A, Nath A, McArthur JC, Halliday W, Power C, Gallo RC, Major EO: Induction of monocyte chemoattractant protein-1 in HIV-1 Tat-stimulated astrocytes and elevation in AIDS dementia. Proc Natl Acad Sci USA 1998, 95:3117-3121.

11. Weiss JM, Nath A, Major EO, Berman JW: HIV-1 Tat induces monocyte chemoattractant protein-1-mediated monocyte transmigration across a model of the human blood-brain barrier and up-regulates CCR5 expression on human monocytes. J Immunol 1999, 163:2953-2959.

12. Albini A, Ferrini S, Benelli R, Sforzini S, Giunciuglio D, Aluigi MG, Proudfoot AE, Alouani S, Wells TN, Mariani G, et al: HIV-1 Tat protein mimicry of chemokines. Proc Natl Acad Sci USA 1998, 95:13153-13158.

13. Nath A, Psooy K, Martin C, Knudsen B, Magnuson DS, Haughey N, Geiger JD: Identification of a human immunodeficiency virus type 1 Tat epitope that is neuroexcitatory and neurotoxic. J Virol 1996, 70:1475-1480.

14. Bansal AK, Mactutus CF, Nath A, Maragos W, Hauser KF, Booze RM: Neurotoxicity of HIV-1 proteins gp120 and Tat in the rat striatum. Brain Res 2000, 879:42-49.

15. Nath A: Human immunodeficiency virus (HIV) proteins in neuropathogenesis of HIV dementia. J Infect Dis 2002, 186(Suppl 2):S193-S198.

16. Maragos WF, Tillman $P$, Jones M, Bruce-Keller AJ, Roth S, Bell JE, Nath A: Neuronal injury in hippocampus with human immunodeficiency virus transactivating protein, Tat. Neuroscience 2003, 117:43-53.

17. Kaul M, Garden GA, Lipton SA: Pathways to neuronal injury and apoptosis in HIV-associated dementia. Nature 2001, 410:988-994.

18. Ranga U, Shankarappa R, Siddappa NB, Ramakrishna L, Nagendran R, Mahalingam M, Mahadevan A, Jayasuryan N, Satishchandra P, Shankar SK, Prasad VR: Tat protein of human immunodeficiency virus type 1 subtype C strains is a defective chemokine. J Virol 2004, 78:2586-2590.

19. Rao VR, Sas AR, Eugenin EA, Siddappa NB, Bimonte-Nelson H, Berman JW, Ranga U, Tyor WR, Prasad VR: HIV-1 clade-specific differences in the induction of neuropathogenesis. J Neurosci 2008, 28:10010-10016.

20. Persidsky $Y$, Limoges J, McComb R, Bock P, Baldwin T, Tyor W, Patil A, Nottet HS, Epstein L, Gelbard H, et al: Human immunodeficiency virus encephalitis in SCID mice. Am J Pathol 1996, 149:1027-1053.

21. Avgeropoulos N, Kelley B, Middaugh L, Arrigo S, Persidsky Y, Gendelman HE, Tyor WR: SCID mice with HIV encephalitis develop behavioral abnormalities. J Acquir Immune Defic Syndr Hum Retrovirol 1998, 18:13-20.

22. Campbell GR, Watkins JD, Singh KK, Loret EP, Spector SA: Human immunodeficiency virus type 1 subtype $C$ Tat fails to induce intracellular calcium flux and induces reduced tumor necrosis factor production from monocytes. J Virol 2007, 81:5919-5928.

23. Gandhi N, Saiyed Z, Thangavel S, Rodriguez J, Rao KV, Nair MP: Differential effects of HIV type 1 clade B and clade C Tat protein on expression of proinflammatory and antiinflammatory cytokines by primary monocytes. AIDS Res Hum Retroviruses 2009, 25:691-699.

24. Wong JK, Campbell GR, Spector SA: Differential induction of interleukin-10 in monocytes by HIV-1 clade B and clade C Tat proteins. J Biol Chem 2010, 285:18319-18325.

25. Mishra M, Vetrivel S, Siddappa NB, Ranga U, Seth P: Clade-specific differences in neurotoxicity of human immunodeficiency virus-1 B and C Tat of human neurons: significance of dicysteine C30C31 motif. Ann Neurol 2008, 63:366-376.

26. Eugenin EA, King JE, Nath A, Calderon TM, Zukin RS, Bennett MV, Berman JW: HIV-tat induces formation of an LRP-PSD-95- NMDAR-nNOS complex that promotes apoptosis in neurons and astrocytes. Proc Natl Acad Sci USA 2007, 104:3438-3443.

27. Liu Y, Jones M, Hingtgen CM, Bu G, Laribee N, Tanzi RE, Moir RD, Nath A, He JJ: Uptake of HIV-1 tat protein mediated by low-density lipoprotein receptor-related protein disrupts the neuronal metabolic balance of the receptor ligands. Nat Med 2000, 6:1380-1387.

28. Li W, Huang Y, Reid R, Steiner J, Malpica-Llanos T, Darden TA, Shankar SK, Mahadevan A, Satishchandra P, Nath A: NMDA receptor activation by HIV-Tat protein is clade dependent. J Neurosci 2008, 28:12190-12198.

29. Lawler K, Mosepele M, Ratcliffe S, Seloilwe E, Steele K, Nthobatsang R, Steenhoff A: Neurocognitive impairment among HIV-positive individuals in Botswana: a pilot study. J Int AIDS Soc 2010, 13:15.
30. Joska JA, Fincham DS, Stein DJ, Paul RH, Seedat S: Clinical correlates of HIV-associated neurocognitive disorders in South Africa. AIDS Behav 2010, 14:371-378

31. Joska JA, Westgarth-Taylor J, Myer L, Hoare J, Thomas KG, Combrinck M, Paul RH, Stein DJ, Flisher AJ: Characterization of HIV-Associated Neurocognitive Disorders among individuals starting antiretroviral therapy in South Africa. AIDS Behav 2011, 15:1197-1203.

32. Holguin A, Banda M, Willen EJ, Malama C, Chiyenu KO, Mudenda VC, Wood C: HIV-1 effects on neuropsychological performance in a resource-limited country, Zambia. AIDS Behav 2011, 15:1895-1901.

33. Grisson RD, Chenine AL, Yeh LY, He J, Wood C, Bhat GJ, Xu W, Kankasa C, Ruprecht RM: Infectious molecular clone of a recently transmitted pediatric human immunodeficiency virus clade $C$ isolate from Africa: evidence of intraclade recombination. J Virol 2004, 78:14066-14069.

34. Gupta JD, Satishchandra P, Gopukumar K, Wilkie F, Waldrop-Valverde D, Ellis R, Ownby R, Subbakrishna DK, Desai A, Kamat A, et al: Neuropsychological deficits in human immunodeficiency virus type 1 clade C-seropositive adults from South India. J Neurovirol 2007, 13:195-202.

35. Tamura K, Peterson D, Peterson N, Stecher G, Nei M, Kumar S: MEGA5: molecular evolutionary genetics analysis using maximum likelihood, evolutionary distance, and maximum parsimony methods. Mol Biol Evol 2011, 28:2731-2739.

36. Kuiken C, Foley B, Leitner T, Apetrei C, Hahn B, Mizrachi I, Mullins J, Rambaut A, Wolinsky S, Korber B: HIV sequence compendium 2010, Volume 10-03684. Los Alamos, New Mexico: Theoretical Biology and Biophysics GroupNM; 2010.

37. Koyanagi Y, Miles S, Mitsuyasu RT, Merrill JE, Vinters HV, Chen IS: Dual infection of the central nervous system by AIDS viruses with distinct cellular tropisms. Science 1987, 236:819-822.

38. Ndung'u T, Renjifo B, Essex M: Construction and analysis of an infectious human Immunodeficiency virus type 1 subtype $\mathrm{C}$ molecular clone. J Virol 2001, 75:4964-4972.

39. Rao VR, Eugenin EA, Berman JW, Prasad VR: Methods to Study Monocyte migration induced by HIV-infected cells. In HIV Protocols. 2nd edition. Edited by Prasad VR, Kalpana GV. Springer; 2009.

40. Mengozzi M, De Filippi C, Transidico P, Biswas P, Cota M, Ghezzi S, Vicenzi E, Mantovani A, Sozzani S, Poli G: Human immunodeficiency virus replication induces monocyte chemotactic protein-1 in human macrophages and U937 promonocytic cells. Blood 1999, 93:1851-1857.

41. Zheng J, Thylin MR, Cotter RL, Lopez AL, Ghorpade A, Persidsky Y, Xiong H, Leisman GB, Che MH, Gendelman HE: HIV-1 infected and immune competent mononuclear phagocytes induce quantitative alterations in neuronal dendritic arbor: relevance for HIV-1-associated dementia. Neurotox Res 2001, 3:443-459.

42. Tyor WR, Power C, Gendelman HE, Markham RB: A model of human immunodeficiency virus encephalitis in scid mice. Proc Natl Acad Sci USA 1993, 90:8658-8662.

43. Griffin WC 3rd, Middaugh LD, Cook JE, Tyor WR: The severe combined immunodeficient (SCID) mouse model of human immunodeficiency virus encephalitis: deficits in cognitive function. J Neurovirol 2004, 10:109-115.

44. Shankarappa R, Chatterjee R, Learn GH, Neogi D, Ding M, Roy P, Ghosh A, Kingsley L, Harrison L, Mullins Jl, Gupta P: Human immunodeficiency virus type 1 env sequences from Calcutta in eastern India: identification of features that distinguish subtype $C$ sequences in India from other subtype C sequences. J Virol 2001, 75:10479-10487.

45. Neogi U, Bontell I, Shet A, De Costa A, Gupta S, Diwan V, Laishram RS, Wanchu A, Ranga U, Banerjea AC, Sonnerborg A: Molecular epidemiology of HIV-1 subtypes in India: origin and evolutionary history of the predominant subtype C. PLoS One 2012, 7:e39819.

46. Neogi U, Gupta S, Sahoo PN, Shet A, Rao SD, Ranga U, Prasad VR: Genetic characterization of HIV type 1 Tat exon 1 from a southern Indian clinical cohort: identification of unique epidemiological signature residues. AIDS Res Hum Retroviruses 2012, 28:1152-1156.

47. Bachu M, Yalla S, Asokan M, Verma A, Neogi U, Sharma S, Murali RV, Mukthey AB, Bhatt R, Chatterjee S, et al: Multiple NF-kappaB sites in HIV-1 subtype $C$ long terminal repeat confer superior magnitude of transcription and thereby the enhanced viral predominance. $J \mathrm{Bio} / \mathrm{Chem}$ 2012, 287:44714-44735.

48. Allavena P, Bianchi G, Zhou D, van Damme J, Jilek P, Sozzani S, Mantovani $A$ : Induction of natural killer cell migration by monocyte chemotactic protein-1, -2 and -3. Eur J Immunol 1994, 24:3233-3236. 
49. Kelder W, McArthur JC, Nance-Sproson T, McClernon D, Griffin DE: Beta-chemokines MCP-1 and RANTES are selectively increased in cerebrospinal fluid of patients with human immunodeficiency virus-associated dementia. Ann Neurol 1998, 44:831-835.

50. Siddappa NB, Venkatramanan M, Venkatesh P, Janki MV, Jayasuryan N, Desai A, Ravi V, Ranga U: Transactivation and signaling functions of Tat are not correlated: biological and immunological characterization of HIV-1 subtype-C Tat protein. Retrovirology 2006, 3:53.

51. King JE, Eugenin EA, Hazleton JE, Morgello S, Berman JW: Mechanisms of HIV-tat-induced phosphorylation of N-methyl-D-aspartate receptor subunit $2 \mathrm{~A}$ in human primary neurons: implications for neuroAIDS pathogenesis. Am J Pathol 2010, 176:2819-2830.

52. Larkin MA, Blackshields G, Brown NP, Chenna R, McGettigan PA, McWilliam $H$, Valentin F, Wallace IM, Wilm A, Lopez R, et al: Clustal W and Clustal X version 2.0. Bioinformatics 2007, 23:2947-2948.

53. Theodore TS, Englund G, Buckler-White A, Buckler CE, Martin MA, Peden KW: Construction and characterization of a stable full-length macrophage-tropic HIV type 1 molecular clone that directs the production of high titers of progeny virions. AIDS Res Hum Retroviruses 1996, 12:191-194.

54. Mochizuki N, Otsuka N, Matsuo K, Shiino T, Kojima A, Kurata T, Sakai K, Yamamoto N, Isomura S, Dhole TN, et al: An infectious DNA clone of HIV type 1 subtype C. AIDS Res Hum Retroviruses 1999, 15:1321-1324.

55. Sas AR, Bimonte-Nelson H, Smothers CT, Woodward J, Tyor WR: Interferon-alpha causes neuronal dysfunction in encephalitis. J Neurosci 2009, 29:3948-3955.

56. Hyde LA, Hoplight BJ, Denenberg VH: Water version of the radial-arm maze: learning in three inbred strains of mice. Brain Res 1998, 785:236-244.

57. Bimonte-Nelson HA, Hunter $\mathrm{CL}$, Nelson ME, Granholm A-CE: Frontal cortex BDNF levels correlate with working memory in an animal model of Down syndrome. Behav Brain Res 2003, 139:47-57.

58. Bimonte HA, Denenberg VH: Estradiol facilitates performance as working memory load increases. Psychoneuroendocrinology 1999, 24:161-173.

59. Jarrard LE: On the role of the hippocampus in learning and memory in the rat. Behav Neural Biol 1993, 60:9-26.

60. Luine $\mathrm{V}$, Rodriguez M: Effects of estradiol on radial arm maze performance of young and aged rats. Behav Neural Biol 1994, 62:230-236.

61. Cohen J: Statistical power analysis for the behavioral sciences. 2nd edition. Hillsdale, N.J.: L. Erlbaum Associates; 1988.

doi:10.1186/1742-4690-10-61

Cite this article as: Rao et al:: Clade C HIV-1 isolates circulating in Southern Africa exhibit a greater frequency of dicysteine motifcontaining Tat variants than those in Southeast Asia and cause increased neurovirulence. Retrovirology 2013 10:61.

\section{Submit your next manuscript to BioMed Central and take full advantage of:}

- Convenient online submission

- Thorough peer review

- No space constraints or color figure charges

- Immediate publication on acceptance

- Inclusion in PubMed, CAS, Scopus and Google Scholar

- Research which is freely available for redistribution

Submit your manuscript at www.biomedcentral.com/submit
C Biomed Central 